\title{
De la novela policial al cine político. Representación del crimen y focalización múltiple en las diferentes versiones de Los albañiles, de Vicente Leñero
}

\author{
From Police Novels to Political Cinema. Representation \\ of Crime and Multiple Focalization in Different Versions \\ of Vicente Leñero's Los albañiles
}

\author{
STEFANO TEDESCHI \\ Sapienza-Università di Roma
}

\begin{abstract}
RESUMEN: La novela de Vicente Leñero, Los albañiles (1964), ha conocido en el tiempo dos transposiciones a otras formas artísticas: una para el teatro (1968) y otra para el cine (1976), ambas firmadas por el mismo autor. El paso de un formato a otro ha provocado cambios significativos en la estructura de la narración y en el enfoque dado a algunos temas. El artículo propone una lectura de estos cambios a partir de la construcción de la novela según la forma de la "focalización interna múltiple" y de las transformaciones de su estructura en las versiones sucesivas.
\end{abstract}

ABSTRACT: The novel Los albañiles (1964) by Vicente Leñero was adapted twice by the same autor, first as a play (1968) and later as a screenplay for the film of Jorge Fons (1976). The transition through the different formats caused relevant changes in the structure of the narration and in the focus about the different themes of the novel. This paper discusses these changes, starting from the construction of the novel as a narration in "multiple internal focalization" and from the changes of this structure in the succesive versions.

PALABRAS CLAVES: Vicente Leñero, cine y literatura, novela policial, literatura mexicana KEYWORDS: Vicente Leñero, Literature and Movies, Crime Novel, Mexican Literature RECIBIDO: 30 de enero de 2018 • ACEPTADO: 30 de abril de 2018 



\section{STEFANO TEDESCHI}

Sapienza-Università di Roma

\section{De la novela policial al cine político. Representación del crimen y focalización múltiple en las diferentes versiones de Los albañiles, de Vicente Leñero}

El título de esta reflexión sobre la representación del crimen declara algo que es en realidad casi una paradoja ontológica, una contradicción que se realiza a partir de la idea misma de que un crimen se pueda representar: de hecho, el acto criminoso, por su naturaleza, tendría que producirse en secreto, fuera de la vista de un público, y su autor, quedar desconocido. En cambio, desde siempre, sociedades con organizaciones y formas de control social muy diferentes han previsto modalidades de representación de acciones criminales, a menudo con finalidades de catarsis colectiva, en especial cuando el crimen se lleva a cabo con violencia, como en los casos de asesinato, violación, torturas etcétera.

Si en épocas anteriores estas representaciones pertenecían al universo de la tragedia o de la épica, cuando, entre los siglos XVIII y XIX, se empiezan a organizar estructuras especializadas destinadas a mantener el orden y a perseguir las rupturas de ese orden, también la representación del crimen se va localizando dentro de un género - al inicio sólo literario y, más tarde, teatral y cinematográfico - dedicado a este tema, que en varios países y en diferentes lenguas tendrá denominaciones diversas, aunque sus características serán similares; en español se llamará "novela policial". Entre esas características comunes destacan: la voluntad explícita de restablecer un orden perdido, de curar la herida producida en el cuerpo social por un individuo (o un grupo de indivi- 
duos), que por las razones más diversas cometió un crimen; la presencia de un personaje principal que se encarga de reconstruir los hechos para identificar a el/los culpable/s, y, finalmente, un desenlace, que normalmente no puede ser otro que el descubrimiento del culpable y su condena por parte de las autoridades. En 1945, Alfonso Reyes dedicó al tema un breve ensayo, y resumía así algunas de las características básicas del género:

De todas las feas denominaciones que han dado en emplearse para cierto género novelístico hoy más en boga que ninguno - novela de misterio, de crimen, "detectivesca", policíaca, policial- prefiero esta última. Las demás, o parecen despectivas, o limitadas, o impropias por algún concepto. [...]

Es el género literario de nuestra época. No pretendí hacer un juicio de valor, sino una declaración de hechos: 1) es lo que más se lee en nuestros días, y 2) es el único género nuevo aparecido en nuestros días, aun cuando sus antecedentes se pierdan, como es natural, en el pasado.

El género policial es un género vergonzante. Todos lo practican, pero el lector sorprendido con una de estas novelas se disculpa diciendo: "No es más que una novela policial", frase que sustituye a la de "No es más que una novela", que, en el siglo XVIII, causaba la indignación de Jane Austen. Ahora bien, si muchos se creen obligados por imperativos de cultura a leer una buena novela de éxito, en cambio la novela policial se lee sin compulsión alguna, y ni siquiera se habla de ella con los vecinos. Tiene las condiciones esenciales del atractivo literario, el placer: acaso motivo más imperioso que el deseo de instruirse o la ineptitud para soportar la presión social que nos rodea. Esta novela es hasta hoy la Cenicienta de la Novela. [...]

Interés de la fábula y coherencia en la acción. Pues ¿qué más exigía Aristóteles? La novela policial es el género clásico de nuestro tiempo (Reyes 1996: 457).

Si en la primera mitad del siglo xx la fortuna del género se inscribe dentro de las coordenadas brevemente resumidas en las líneas anteriores, y se empiezan a rodar películas inspiradas en los autores más conocidos, sobre todo británicos y franceses, a partir de los años cuarenta la función de las novelas como ejemplos de la restauración de un orden se va perdiendo poco a poco; la novela policial empieza a tener un papel de crítica social más acentuado, y la búsqueda de una verdad aceptada 
por todos los protagonistas se vuelve cada vez menos fácil; no será un caso que para la definición del género se empiecen a utilizar los términos de "novela negra", o de "cine noir". Este cambio se había empezado a vislumbrar ya en una modalidad narrativa peculiar, que en el siglo XIX había conocido por lo menos dos ejemplos de un cierto renombre en lengua inglesa, la novela The moonstone, de Wilkie Collins y el poema narrativo The Ring and the Book, de Robert Browning; en esta variante, la narración de los hechos delictivos se da en forma de testimonios repetidos acerca del mismo evento, y la acumulación de puntos de vista diferentes, a veces encontrados, lleva al final al descubrimiento de una verdad casi siempre opuesta a la que el lector $-\mathrm{y}$ algunos de los protagonistas - se esperaría. En estos casos, el culpable inicialmente acusado del crimen se revela inocente, cuando no, una víctima de un error judicial.

En 1972 Gérard Genette, en su libro Figuras III, dedica una sección a la clasificación de los puntos de vista, ahí definió este tipo de narración como caracterizada por lo que él llamó "focalización interna multiple": una forma narrativa que, por supuesto, no reitera simplemente el mismo sintagma verbal, o, la misma escena un cierto número de veces, sino que, a través de esta modalidad, permite apreciar los cambios causados por la diferencia del punto de vista. En los mismos años, la relación entre repetición y cambios fue estudiada por Jacques Lacan y Gilles Deleuze, y se relacionó con la figura retórica clásica de la epanortosis, la "repetición con variaciones".

Si retomamos la definición de Genette, notamos cómo al final de la cita el autor francés ejemplifica el subgénero a través de una película, único caso de este tipo a lo largo de toda la trilogía dedicada a las figuras del discurso, como si el arte cinematográfico fuera el más adecuado para este tipo de narraciones:

Así pues, vamos a rebautizar el primer tipo, el que representa en general el relato clásico, relato no focalizado o de focalización cero. El segundo será el relato de focalización interna, ya sea fija [...], variable [...] o múltiple, como en las novelas epistolares, en que se puede evocar el mismo acontecimiento varias veces según el punto de vista de varios personajes epistológrafos; sabido es que el poema narrativo de Robert Browning El anillo y el 
libro (que cuenta un caso criminal visto sucesivamente por el asesino y las víctimas, la defensa, la acusación, etc.) ha sido considerado durante años como ejemplo canónico de ese tipo de relato, antes de que lo suplantara para nosotros la película Rashomon (Genette 1989: 190).

La sucesiva reflexión crítica ha vuelto a replantear muchas de las definiciones de Genette, con discusiones que se han interesado, sobre todo, en el concepto mismo de focalización y, sin embargo, la focalización interna múltiple no ha sido especialmente reconsiderada, por lo menos hasta los años noventa, cuando, sobre todo en el área alemana, algunos teóricos han ido proponiendo nuevas arquitecturas interpretativas, entre las cuales destaca para nuestros propósitos la de Manfred Jahn, que a partir del Prólogo de Henry James a su Retrato de Señora (1881), considera la construcción narrativa a través de lo que él define como "ventana de focalización":

La teoría de la focalización, se ocupa del grado de posibilidad de una ventana del texto sobre los eventos de una historia [...] Si la ventana de la focalización se sitúa en el origen narrativo, la lectura usual será que el narrador está hablando sobre lo que él o ella percibe imaginativamente. [...] Para una focalización basada en una ventana narrativa, la percepción natural será que el texto representa (o, en el caso de un narrador perceptible, que el narrador recuerda) lo que el reflector percibe, sea in actu o imaginativamente (Jahn 1996: 256).

En su trabajo, Jahn transforma la focalización interna múltiple en un edificio ficcional con muchas ventanas que se van abriendo al mismo tiempo - o en momentos sucesivos - sobre la misma escena, como si fuera posible verla desde diferentes ángulos visuales; las historias narradas de esta manera pueden seguir un orden cronológico o un orden arbitrario y casual; resulta evidente cómo esta propuesta de Jahn se aplica de manera muy productiva a la narración cinematográfica, cuando, por ejemplo, una misma escena puede ser reiterada cambiando la posición de la cámara, como ocurre, justamente, en la película de Kurosawa $\mathrm{y}$ en todas las que se han inspirado en ella.

En la literatura hispanoamericana, la novela policial, en su versión "clásica", ha conocido un desarrollo original bastante tardío, aunque el 
tema de la representación de la violencia ha marcado gran parte de los textos paradigmáticos aparecidos en el continente. Ya desde las Crónicas de la Conquista; la compleja dialéctica entre la violencia perpetrada por los representantes de las instituciones y los elementos rebeldes y subversivos de la sociedad, así como la instabilidad política que, durante el siglo XIX y principios del XX caracterizó a muchos países latinoamericanos, han influido posiblemente en este retraso, posteriormente, también marcó la ausencia en la novela negra continental de grandes figuras de detectives pertenecientes a los cuerpos de las policías oficiales.

Los ejemplos de modalidad narrativa de la focalización interna múltiple no son muy abundantes y, entre ellos, habrá que recordar en especial: Rosaura a las diez, de Marco Denevi (1955); Los albañiles, de Vicente Leñero (1963), y Crónica de una muerte anunciada, de Gabriel García Márquez (1982); todas ellas conocieron versiones fílmicas, y en los primeros dos casos los autores colaboraron en la escritura del guion.

En 1963 la novela de Leñero ganó el Premio Biblioteca Breve, fue llevada al teatro por el mismo autor en $1968 \mathrm{y}$, posteriormente, a la pantalla grande en 1976, bajo la dirección de Jorge Fons, con un guion firmado por el director, Jorge Carrión, y, como hemos dicho, el mismo Leñero.

La novela, y las versiones siguientes, nacen del asesinato de don Jesús, velador de un edificio en construcción en la capital del país, un personaje de muy dudosa moralidad, alrededor del cual se mueve toda una muestra de los tipos sociales del México de los años sesenta: albañiles, obreros, jóvenes aprendices, los dueños de las fincas y de los edificios en construcción, los políticos y los curas, y, claramente, un grupo de policías, en un momento histórico en que la capital mexicana estaba conociendo su máximo crecimiento urbanístico.

Mientras en los ejemplos mencionados anteriormente - las novelas inglesas, la de Denevi y la película de Kurosawa-, los diversos testimonios se van sucediendo en un orden más o menos lógico y cronológico, de manera que el lector / espectador pueda reconstruir el flujo de los eventos, en la novela de Leñero los diferentes testigos hablan uno detrás del otro de manera confusa, sin una bien definida línea temporal, ni una voz narrativa homogénea que vaya hilvanando los diferentes puntos de vista; como ha evidenciado la crítica, el escritor mexicano toma más 
como punto de referencia el Nouveau roman francés, que los ejemplos "clásicos" de la novela policial. De esta manera, a lo largo de los 11 capítulos de la novela varias voces se van cruzando, y, al final, resulta imposible para los policías, y para el lector, definir un culpable, ya que todos los sospechosos tuvieron la ocasión y el móvil para asesinar a don Jesús.

Leñero recordó en una entrevista cómo en su proyecto narrativo había una voluntad metafórica de tipo religioso, que irá adquiriendo importancia, como se verá, en las versiones sucesivas:

En ese ambiente antirreligioso del que hablaba, escribí, en 1962, Los albañiles, una simple metáfora de Jesucristo. Recuerdo que traté de explicarle el sentido religioso de mi novela a Ramón Xirau, creyente, por cierto, y me dijo que me dejara de elucubraciones. Mi novela era tal como era. No necesitaba añadirle supuestas alegorías cristológicas. Nadie la entendía como yo hubiera querido. El protagonista es un velador inspirado en aquello de san Pablo: del Jesucristo que no solo carga con todos los males del mundo, sino que se hace pecado para asumirlo todo" (Salinas 1997: 82-83, en Torres 2015: 59).

En su lectura de la obra, Humberto Robles, sin embargo, se acerca a este significado metafórico, cuando afirma que "la novela es una interpretación artística de una de las coordenadas básicas de la condición humana: la fútil búsqueda de la verdad absoluta" (Robles 1970: 579); a lo largo de los años, otras posibles líneas interpretativas han sido desarrolladas por la crítica: el tratamiento del tiempo, la búsqueda y la definición de una identidad personal, así como las relaciones entre ética y esencia. Josefina Ludmer ha propuesto otro análisis, que considera justamente la posición del detective: "El hombre de la corbata a rayas", como se le llama en los primeros diez capítulos de la novela, es el policía encargado de la investigación que quiere usar métodos científicos para averiguar quién mató a don Jesús, impidiendo a sus colegas emplear la violencia indiscriminada durante los interrogatorios. Toda la acción llevada a cabo por el detective se resume en preguntar y escuchar; la escena del crimen y sus personajes se manifiestan dentro de este espacio dialógico, en el cual el protagonista se sitúa en una zona liminar, al mismo tiempo dentro y fuera del espacio novelesco, una marginalidad 
que marca una diferencia, como si él no quisiera finalmente descubrir al culpable del asesinato - ya que resulta imposible definirlo con absoluta certeza - , sino desenmascarar las relaciones ambiguas entre ficción y realidad:

Pero la función más importante del detective de Los albañiles es reconocer precisamente que la ficción es ficción. Es el límite entre la irrealidad y lo real; es el que se encarga de señalar la irrupción de la realidad en el mundo imaginario; de negar la ficción en tanto realidad o de reconocerla como ficción. Esto no significa que, en el interior de Los albañiles, el detective "represente" la realidad - nadie representa nada en una novela -; simplemente es el que está fuera de la ficción y fuera del mundo elaborado por la ficción; es el no englobado por la historia. La bipolaridad no es mundo imaginario frente a realidad (o inconsciente frente a conciencia o cuerpo frente a mente, como podría pensarse esquemáticamente) sino, desde el ángulo del narrador, interioridad y exterioridad dentro de la ficción misma (Ludmer 1972: 197).

En los textos caracterizados por la focalización interna múltiple, la narración se organiza a través de una serie de repeticiones que ponen en entredicho la fiabilidad de los testimonios sucesivos, y en Los albañiles esta falta de credibilidad aumenta según los intereses personales de los diferentes personajes. Cuando en el último capítulo el detective recupera su nombre - sabremos que se llama Munguía - y empieza a resumir toda la información que ha ido acumulando, volviéndose así el narrador implícito de la historia, no puede más que recrear por cinco veces la escena del homicidio, cada vez con un culpable diferente, y la repetición construye una estructura en forma de espiral donde todas las pruebas recogidas en las páginas anteriores no hacen nada más que señalar las versiones contrastantes, sin poder llegar a una verdad definitiva; no funcionan como pruebas de una posible verdad, sino como fragmentos de una realidad que es imposible reconstruir. Munguía juega así el papel de catalizador de todas las versiones recogidas a lo largo del texto, pero no consigue restaurar el orden social roto por el crimen. El mundo descrito en la novela está plagado de crímenes - estafas, robos, traiciones, acosos sexuales, violaciones - y el asesinato de don Jesús llega a ser el símbolo de una generalizada depravación colectiva, para la cual no 
puede haber un solo culpable, a menos que no sea un chivo expiatorio, artificialmente construido por el sistema de control social.

Leñero volverá sobre este tema en un texto muy posterior, que leyó en el Encuentro Internacional de Literatura Policiaca, en 1987 en San Juan del Río, Querétaro, cuando habló de las dificultades para escribir en México una novela policial:

En México, los inspectores de policía (agentes policiacos en cualesquiera de sus niveles) son literariamente inverosímiles y muy poco tienen que ver con los personajes clásicos del género. A los inspectores de policía mexicanos - desde el más talachero agente investigador hasta los mismísimos procuradores de justicia - les interesa encontrar un culpable, no descubrir al culpable. El caso queda totalmente resuelto cuando un asesino confiesa, "canta", lo que el agente quiere que confiese no lo que estrictamente corresponde a la verdad. Aquí nadie va tras el asesino pacientemente, paso a paso, pista a pista; la autoridad espera que el maldito caiga "cualquier día de estos", como de milagro. [...] En México, los crímenes no se resuelven; son excepcionales, insólitos - absoluta minoría - los casos en verdad aclarados. Lo común, lo cotidiano, lo constatable es el crimen impune, el expediente eternamente abierto, el asunto que no se aclaró, ni se investigó, ni se resolvió jamás. [...] No termine forzosamente su novela resolviendo el crimen. Recuerde que en la realidad mexicana es más frecuente $-\mathrm{y}$ por lo tanto más verosímil: y por lo tanto más literario, digan lo que digan los preceptores del género o los moralistas oficiales - el expediente abierto, inconcluso. No crea en la vieja receta de que toda novela policiaca debe terminar con la solución del caso planteado. Ese es un precepto moral, no un precepto literario (Leñero 2014: 6).

Cuando en 1968 Leñero estrenó la versión teatral de la novela, el papel del detective Munguía, como buscador de esta "verdad absoluta", resultará mucho menos relevante, mientras que irá adquiriendo más importancia el personaje del velador. El mismo autor hizo notar este cambio, cuando en una entrevista propuso una lectura de don Jesús como un "redentor sui generis" (Leñero cit. en Grossman, 7), volviendo a la intuición originaria del velador como víctima expiatoria. En efecto, el tema central de la pieza no es la búsqueda de una verdad posible, sino la presentación de un personaje que, asumiendo en sí todos los males del 
mundo, se vuelve el chivo expiatorio de una sociedad enferma y corrupta. En la sucesiva versión cinematográfica la excelente interpretación de Ignacio López Tarso en el personaje de don Jesús acentuará aún más este aspecto, mientras que el personaje de Munguía (Eduardo Casab) se esfuma en un anónimo y olvidable policía burgués.

Si las diferentes versiones del asesinato se pueden leer en la novela como percepciones contradictorias de una misma realidad, en la obra teatral y en la película se vuelven las máscaras, las ficciones detrás de las cuales cada personaje esconde su posible y peculiar responsabilidad. En la última escena de la obra teatral Munguía enumera las seis posibles soluciones del caso, como si todos los implicados fueran culpables; mientras tanto, el espectador ve al velador luchando en silencio contra una sombra, un enemigo invisible, detrás del cual se esconde una culpa colectiva, una realidad social donde nadie es verdaderamente inocente:

(Celerina sale corriendo. Isidro va tras ella, pero antes de salir se detiene y queda inmóvil en un ángulo de la obra. En otros puntos del edificio empiezan a perfilarse Chapo, Sergio, Jacinto, Patotas y Federico. Todos permanecen inmóviles, como fantasmas, durante el parlamento de Munguía.)

Munguía -(Afiebrado, dirigiéndose a ellos.) ¡Asesinos! (Señala a Patotas.) Fue usted. No pensaba hacerlo, pero el viejo se puso necio y lo amenazó. Usted había ido a la bodega solo por la cartera del Nene, porque necesitaba esos tres mil mugrosos pesos. (Señala a Federico.) Porque necesitaba entregar las relaciones a su padre y porque solo yendo a contar tabique por tabique, bulto por bulto, mosaico por mosaico, podía rectificar sus cálculos. No quería matarlo. Fue la risa del viejo: ingenierito estúpido, ingenierito estúpido, ingenierito estúpido. (Señala al Chapo.) Fueron sus fanfarronadas, sus amenazas, el miedo a que denunciara sus robos. Usted era el amo y tenía que darle una lección a él y a su mujer, a la mujer que lo había despreciado. (Señala a Jacinto.) De no haber estado tan borracho, no se hubiera atrevido. El alcohol le alborotaba los recuerdos y lo hacía pensar en su hijo, igualito a Isidro, que se quedaba todas las noches con el viejo. Su propio hijo en manos de un infeliz degenerado. (Señala a Isidro.) Eso era y tú no querías darte cuenta. Las cosquillas y las travesuras no eran caricias; eran una porquería y tú fuiste un puerco: le llevaste a tu novia para que el velador, antes que tú, le rompiera las enaguas. (Señala a Sergio.) De nada sirvieron regaños, sermones y rezos para ahuyentar al demonio. El demonio contaminó el cuerpo 
de su hermana y lo convirtió a usted en otro demonio siete veces peor. Usted ya no era de Dios sino del demonio. El demonio estaba en usted, y usted fue a la bodega, descendió a los infiernos para matar a don Jesús (Sale de escena.) (Leñero 1970: 59).

La epanortosis, la "repetición con variaciones" del asesinato, crea en este breve monólogo una confusión total respecto a posibles responsabilidades individuales, generada principalmente por la concentración temporal en que se suceden las palabras de Munguía: los móviles se acumulan uno detrás del otro, consecutivamente, y la originaria finalidad de la antigua figura retórica - la posibilidad de llegar a una explicación a través de la repetición - se revierte totalmente: la reiteración no resuelve el misterio, sino que lo complica aún más, y lo vuelve indescifrable.

En la obra teatral las mismas indicaciones para la construcción del escenario producen el mismo efecto de interacción sobre la repetición de los eventos:

Las violaciones de tiempo y de espacio que cometen los personajes al cruzar del área policial a la zona del edificio, o viceversa, deben entenderse como eso: como violaciones cronológicas y espaciales, como súbitos rompimientos que solo justifica la unidad psicológica que rige los acontecimientos de la historia (Leñero 1970: 2).

De esta manera, Leñero intenta resolver la transformación de la estructura de la novela, imaginando una solución visual a la focalización múltiple. Cuando uno de los sospechosos declara su versión de los hechos dentro del espacio policial, de un lado del escenario, al otro lado -el del edificio en construcción - se representa lo que él está contando, de manera que el público se encuentre delante de dos ventanas abiertas sobre la misma historia.

La película de Jorge Fons se filmó en 1976, se estrenó en noviembre del mismo año, y en 1977 recibió el Oso de Plata en el Festival Internacional de Berlín. Como se ha dicho antes, Leñero colaboró en la escritura del guion, que se publicó en 1982 en volumen separado. ${ }^{1}$ En la trasposición

El volumen de la editorial Marcha lleva como título en la portada solo la expresión "Tres guiones cinematográficos", mientras en el interior se añade otro título: "Justos 
de las dos obras anteriores a la pantalla grande, el efecto de confusión se intensifica, ya que el guion prevé muchas escenas colectivas, donde las voces de los albañiles y de los obreros se superponen, se entrecruzan y se multiplican las frases de doble sentido, con alusiones repetidas a varias formas de prevaricación, que corresponden a todos los niveles sociales, y que marcan todas las relaciones interpersonales. Esta superposición de voces permite también representar una pluralidad de categorías sociales, imagen de las marcadas diferencias regionales y de clase que se podían encontrar en la capital del país en los años sesenta.

En la película, muchas de las preocupaciones de tipo narrativo y estructural que se han evidenciado tienden a desaparecer, mientras aumenta el énfasis sobre el matiz social de la historia. Si en la novela, la búsqueda de una "verdad absoluta" es uno de los temas principales; y, en la versión teatral, la transformación de don Jesús es un símbolo de tipo religioso que cobra un papel relevante, la película se focaliza en la descripción de un derrumbe urbano y de una corrupción que infecta a todos los componentes de la sociedad. Aquí no se trata de un debate filosófico: la realidad de la ciudad de México, presentada en todas sus contradicciones y escándalos, choca con un orden social solo aparente, que deja detrás de sí un cierto número de víctimas, representadas simbólicamente por el velador. Por esta razón, en la película el crimen se muestra con toda su cruel evidencia: al comienzo de la cinta, una toma subjetiva sigue al velador dentro del edificio, lo va persiguiendo como si fuera el asesino, para terminar enseñando la sangre de don Jesús que se derrama por las escaleras (Leñero 1982: 103).

En el guion, sin embargo, la definición del personaje de don Jesús como víctima seguía vigente, a través de una serie de rápidos flashbacks que mostraban episodios de la vida anterior del velador: la infancia, la juventud, la reclusión en un manicomio. Como se advierte en la publicación del texto "durante el proceso de edición se terminaron suprimiendo todas las secuencias relacionadas con la historia pretérita de don Jesús"; de esta manera, en la película ya no hay víctimas o victimarios, sino una sola maquina infernal que produce solo una imparable tragedia colectiva.

por pecadores. Tres guiones cinematográficos”, que reúne así a los tres textos bajo un tema unificador. 
Si en la versión cinematográfica, la focalización múltiple y la técnica de la repetición resultan minimizadas respecto a la novela y a la obra teatral, Fons, Carrión y Leñero denuncian aquí una responsabilidad colectiva y social del crimen, simbolizada por el edificio en construcción, que se vuelve el símbolo de una sociedad en crecimiento, que, al mismo tiempo, acumula edificios y machaca a sus constructores.

A pesar de esta visión tan sombría, la película contiene dos elementos, ausentes en los otros textos, que abren perspectivas diferentes sobre el desenlace de la historia. Por un lado, una atención visual muy marcada por los aspectos materiales de la vida de los albañiles; sobre todo en la parte central de la película escenas muy largas están dedicadas a la representación de su trabajo, con una aplicación documental sobre los detalles que enfatiza el papel de estos protagonistas anónimos del crecimiento urbano, así como, por lo menos en dos escenas, se alude claramente a las reivindicaciones económicas de este colectivo.

En el mismo sentido, resulta significativa la diferencia entre los finales de las tres versiones, donde la novela y la obra teatral terminan con la misma escena: el detective vuelve al lugar del crimen y encuentra un personaje anónimo, que resulta ser el (¿nuevo?) velador del edificio:

- ¿Buscaba a alguien?

- ¿Es usted el velador?

-Sí - dijo el hombre-.¿Qué se le ofrece?

Munguía lo miró de arriba abajo.

-Nada - Avanzó un paso más. Sonrió-. Nada...-Y le puso una mano en el hombro-

(Leñero 1964: 250).

[...] Munguía entra en el edificio. Lo observa con atención. Sube por los andamios. De pronto se detiene en seco. Frente a él, de espaldas al público, se encuentra un hombre abrigado con la cobija del viejo. Tiene su sombrero. Es quizás el mismo don Jesús pero no es posible afirmarlo categóricamente. Munguía se aproxima.

El HOMBRE: ¿Buscaba a alguien?

(Munguía avanza hacia él.)

Munguía: ¿Es usted el velador de este edificio? 
El HOMBRE: ¿Qué se le ofrece?

Munguía: Nada. (Llega hasta él. Con gesto cordial le pone una mano sobre el hombro.) Nada, amigo

(Leñero 1970: 59-60).

En la escena final de la película, como se describe en el guion, este encuentro vuelve a repetirse, pero no es el último fotograma, sino que se añade otra escena, donde se asoma una esperanza que en los otros textos no había: la muerte de don Jesús se rescata con el nacimiento de un niño y el edificio ya no es un andamiaje de vigas y baldosas, sino un edificio terminado que acoge jóvenes habitantes:

Munguía llega al edificio recién concluido. Sobre la fachada se advierten los característicos cordones de banderitas triangulares. Contempla largo tiempo la fachada y avanza hasta la reja que protege la entrada. Al fondo, por entre los barrotes, descubre a un hombre envuelto en un sarape. La oscuridad le impide observar su aspecto.

HOMBRE: ¿Buscaba a alguien?

Munguía: ¿Es usted el velador?

HOMBRE: ¿Qué se le ofrece?

Munguía no responde. Vuelve la espalda y cruza la acera, alejándose.

En el último piso del edificio se enciende una luz. Por la ventana iluminada se observa a una mujer joven en el momento de inclinarse sobre una cuna. Tras ella se encuentra un hombre joven. La mujer levanta a un pequeño niño al que palmea cariñosamente al tiempo que el hombre oprime suavemente la cintura de la mujer

(Leñero 1982: 201).

La escena final de la película, no prevista en el guion, añade otro elemento a esta perspectiva: mientras sigue la música que acompaña toda la escena anterior - la ouverture del Alceste, de Christopher Glück - y pasan los créditos finales, la cámara pasa en reseña, con un rápido trávelin, a los albañiles que ofrecen sus servicios delante de una verja de una iglesia, desde las puertas de la cual entran y salen otros albañiles, que están evidentemente trabajando en ella. Los trabajadores, que han sido, a lo largo de las tres versiones de la historia, descritos como víctimas, posibles culpables, antihéroes anónimos, al final de la película se vuelven los únicos protagonistas reales, la única fuerza fiable en el derrumbe generalizado. 


\section{Bibliografía}

Denevi, Mario (1955). Rosaura a las diez. Buenos Aires, Guillermo Kraft.

FrANKEN, Clemens A. (2010). "Vicente Leñero y el fracaso de su inspector", Literatura y Linguíística, 21: 13-28.

GenetTe, Gerard (1989). Figuras III. Barcelona, Lumen (Figures III, París, Editions du Seuil, 1972).

Grossman, Lois S. (1976). "Los albañiles, Novel and Play: A Two-Time Winner", Latin American Theatre Review, 9.2. University of Kansas: 5-12.

JAHN, Manfred (1996). "Windows of Focalization. Deconstructing and Reconstructing a Narratological Concept", Style, 30, University of Arkansas: 241-267.

LEÑERO, Vicente (1964). Los albañiles. Barcelona, Seix Barral.

LEÑERO, Vicente (1970). Los albañiles. México, Joaquín Mortiz.

LEÑERo, Vicente (1982). Tres guiones cinematográficos. El magnicidio; Los albañiles; Cadena Perpetua. México, Marcha Editores.

LEÑERO, Vicente (2014), "Instrucciones para escribir en México", Filias, 4 de diciembre 2014, <http://www.milenio.com/filias/Vicente_Lenero-instruccion_para_escribir_en_Mexico_0_421157892.html>, consultado por última vez el 30 de mayo de 2018.

LUDMER, Josefina (1972). "Vicente Leñero, Los albañiles. Lector y actor", en Jorge Lafforgue (ed.), Nueva novela latinoamericana. Buenos Aires, Paidós: 194-208.

REYES, Alfonso (1996). "Sobre la novela policial” (1945), en Obras completas, $I X$. México, Fondo de Cultura Económica.

RoBles, Humberto (1970). "Aproximaciones a Los Albañiles de Vicente Leñero", Revista Iberoamericana, 36.73. Estados Unidos, University of Pittsburg: 579-599.

Salinas, Adela (1997). Dios y los escritores mexicanos, Nueva Imagen, México, citado por Vicente Francisco Torres (2015). "Leñero y la narración policial”, Revista de la Universidad de México, núm. 131: 59-61. 